\title{
Determination of the Mechanism of Electrocatalytic Water Oxidation by a Dimanganese Tetrakis-Schiff Base Complex: Comparison of Density Functional Theory Calculations with Experiment
}

\author{
James R. Buchwald, Subhadeep Kal, and Peter H. Dinolfo* \\ Department of Chemistry and Chemical Biology, Rensselaer Polytechnic Institute, 110 Eighth Street, Troy, New York 12180, United \\ States
}

\author{
Supporting Information
}

\begin{abstract}
We have recently reported a new class of tetrakis-Schiff base macrocycles bearing a dimanganese-oxo cluster capable of catalyzing the oxidation of water to $\mathrm{O}_{2}$. Herein we report the applicability of unrestricted density functional theory (DFT) using the B3LYP hybrid functional and the broken symmetry (BS) formalism for the prediction of thermodynamic properties of the proton-coupled electron transfer (PCET) steps involved in the electrocatalytic cycle. We characterize a series of three oxidations of the acetate-

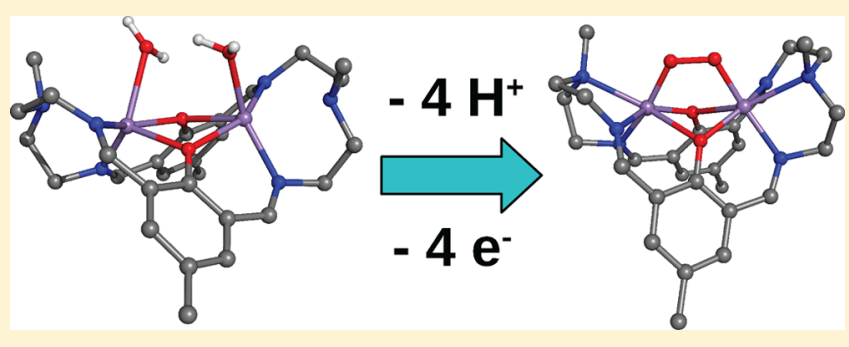
bound catalyst $\left[\mathrm{Mn}^{\mathrm{II}}{ }_{2} \mathrm{LAc}\right]^{+}$in acetonitrile solution in terms of standard reduction potentials, and we show that the predicted thermodynamic results are in good agreement with experiment. We further apply this model to the prediction of reaction thermodynamics in the electrocatalytic cycle of the aqua-bound catalyst $\left[\mathrm{Mn}_{2}^{\mathrm{II}} \mathrm{L}\left(\mathrm{OH}_{2}\right)_{2}\right]^{2+}$, and we locate the most energetically favorable pathway for the oxidation of water by this catalyst. We show upon removal of four protons and four electrons that the remaining oxygen atoms approach to a distance of $1.397 \AA$ with the formation of an O-O single bond.
\end{abstract}

\section{INTRODUCTION}

There is an imperative need in the 21st century to develop fuels which are renewable, carbon-free, and clean. Many scientists are now looking to plants to obtain model systems for the conversion of renewable solar energy to fuels. ${ }^{1}$ Photoautotrophs combine sunlight, water, $\mathrm{O}_{2}$, and $\mathrm{CO}_{2}$ into sugars using a cascade of enzymes and cofactors. One of the important steps in this process is the use of sunlight to oxidize water according to the half-reaction $2 \mathrm{H}_{2} \mathrm{O} \rightarrow \mathrm{O}_{2}+4 \mathrm{H}^{+}+4 \mathrm{e}^{-}$as mediated by the oxygen-evolving complex (OEC) of PSII, an $\mathrm{Mn}_{4} \mathrm{CaO}_{x}$ cluster subject to much ongoing research., ${ }^{2,3}$

The study of transition metal complexes featuring oxomanganese clusters provides a way to uncover the intricate four-electron, four-proton mechanism by which the OEC oxidizes water to molecular oxygen which has so far proven challenging to elucidate. ${ }^{3}$ Further, the study of such systems provides insight into how such complexes can be tuned and optimized to create stable and efficient single-site catalysts for practical solar fuel conversion applications.

We have previously investigated a new class of macrocyclic tetrakis-Schiff base dimanganese complexes (Scheme 1) as potential mimics for the OEC., ${ }^{4,5}$ Electrochemical analysis of $\left[\mathrm{Mn}_{2} \mathrm{LAc}\right]^{+}$reveals two chemically reversible metal-centered and two irreversible ligand-centered (phenolate) oxidations which were confirmed by spectroscopic methods following chemical oxidation. ${ }^{4}$ Subsequent studies of $\left[\mathrm{Mn}_{2} \mathrm{~L}\right]^{2+}$ revealed promising electrocatalytic and photosensitized water oxidation activity. ${ }^{5}$ An electrocatalytic wave was observed in cyclic voltammetry $(\mathrm{CV})$ scans of $\left[\mathrm{Mn}_{2} \mathrm{~L}\right]^{2+}$ at $+1.8 \mathrm{~V}$ vs $\mathrm{NHE}$ in
Scheme 1. Lewis Structures of $\left[\mathrm{Mn}_{2}^{\mathrm{II}} \mathrm{L}\right]^{2+}$ (Left) and $\left[\mathrm{Mn}_{2}{ }_{2} \mathrm{LAc}\right]^{+a}$

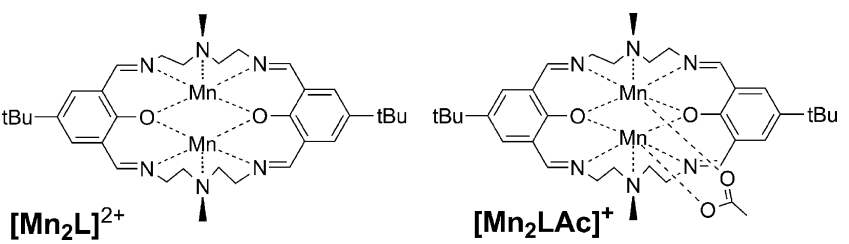

${ }^{a}$ Counterions have been omitted for clarity. Figure adapted from previous work. $^{5}$

propylene carbonate (PC) with $\mathrm{H}_{2} \mathrm{O}$ added as a substrate. Additionally, $\mathrm{O}_{2}$ was detected following controlled potential electrolysis. Similar electrochemical scans were obtained in acetonitrile $(\mathrm{MeCN})$. Catalytic water oxidation could be achieved through photosensitization with $\left[\mathrm{Ru}(\mathrm{bpy})_{3}\right]^{2+}$ and persulfate in $\mathrm{MeCN} \cdot \mathrm{H}_{2} \mathrm{O}$ mixtures as well. In these studies we observed that while the complex was able to catalyze the oxidation of water it did so with low thermodynamic efficiency and turnover number.

In order to optimize this complex for water oxidation, we require insight as to the nature of the intermediates. While experimental studies have allowed us to make broad qualitative

Received: June 10, 2014

Revised: September 22, 2014

Published: October 19, 2014 
assignments, density functional theory (DFT) studies correlated with experimental data will provide better insight into this problem. DFT studies have been widely used for the prediction of reaction thermodynamics including redox potentials. ${ }^{6-11}$ Recently, a number of computational studies using density functional theory to model water oxidation have been reported for homogeneous catalysts, ${ }^{12-14}$ nanoparticles, ${ }^{15}$ and semiconductor oxide surfaces. ${ }^{16,17}$ We have used unrestricted DFT with the ubiquitous B3LYP hybrid functional and a Pople-style triple- $\zeta$ basis set to obtain the geometries of the intermediates in the gas phase, followed by single-point calculations using a larger basis set and an implicit solvation model, to find the free energies of reaction in solution. This model was able to successfully reproduce the thermodynamics of the electrochemistry of $\left[\mathrm{Mn}^{\mathrm{II}}{ }_{2} \mathrm{LAc}\right]^{+}$in acetonitrile. We then used this model to predict the thermodynamics of the electronic ground states of the most probable intermediates in the catalytic cycle, and a minimum-free-energy pathway in good agreement with experiment has been located.

\section{THEORETICAL METHODS}

Electronic Structure Calculations. All electronic structure calculations were performed using the Gaussian 09 software, Revision D.01. ${ }^{18}$ Calculations were performed on the Trestles XSEDE cluster at the San Diego Supercomputing Center and on the Blacklight supercomputer at the Pittsburgh Supercomputing Center. The initial geometry for $\left[\mathrm{Mn}_{4}^{\mathrm{II}} \mathrm{LAc}\right]^{+}$was obtained from a previous X-ray diffraction study; ${ }^{4}$ other initial geometries were adapted from other DFT calculations. In all cases, $t$-butyl groups were replaced by methyl groups as an approximation to improve performance; this was justified by the similar Hammett $\sigma$ parameters $\left(\sigma_{\text {para }}=-0.170 \pm 0.02\right.$ vs $-0.197 \pm 0.02$ for methyl vs $t$-butyl, respectively). ${ }^{19}$ Minimum energy geometries were obtained within the broken symmetry (BS) formalism ${ }^{20}$ using the unrestricted Becke three-parameter Lee-Yang-Parr hybrid density functional (B3LYP); ${ }^{21}$ the 6$311 \mathrm{G}^{* *}$ all-electron basis set for carbon, nitrogen, and hydrogen; ${ }^{22}$ and the $6-311 \mathrm{G}$ all-electron basis set with one $\mathrm{f}$ and two $d$ polarization functions on oxygen and manganese. $^{22,23}$ The resulting geometries were confirmed as minima using analytical frequency calculations at the same level of theory. We have also tested the geometry optimizations with a similar basis set treating manganese at the $6-311 \mathrm{G}^{* *}$ level; however, we found that this basis set was not sufficient to accurately determine the minimum-energy structure of $\left[\mathrm{Mn}_{2}^{\mathrm{II}}{ }_{2} \mathrm{LAc}\right]^{+}$. In both cases, the inclusion of one set of diffuse functions did not make a significant difference in energy. Singlepoint energies at the minimized geometries were calculated using Dunning's correlation-consistent triple- $\zeta$ basis set (ccpVTZ). ${ }^{24}$ Solvation effects were treated implicitly using the Integral Equation Formalism variant of the Polarizable Continuum Model (IEFPCM) ${ }^{25}$ using atomic radii from the UFF force field scaled by a factor of 1.1. The free energy of solvation in acetonitrile, $\Delta G_{\text {sol }}$, was computed from a singlepoint energy calculation at this level of theory using the ccpVTZ basis set, a static dielectric constant of $\epsilon=35.688$, and a dynamic dielectric constant of $\epsilon_{\infty}=1.806874$. Additional geometry optimizations within the PCM model did not make a significant difference in solvation energy or results. In using an implicit solvation model, any nonelectrostatic solvent effects (such as hydrogen bonding), with the exception of cavitation, were neglected. Bond order analyses were performed at the same level of theory as geometry optimization using the AOMix software package. ${ }^{26,27}$ The location of each oxidation (metal- or ligand-centered) was determined from the electron density around the $\mathrm{Mn}$ atoms as analyzed by Bader's theory of Atoms in Molecules. ${ }^{28}$ The Atoms in Molecules analysis was performed using the Multiwfn software package, version $3.3 .3 .^{29}$

Calculation of Magnetic Coupling. As previously noted, calculations were performed within the BS formalism to account for possible antiferromagnetic exchange coupling between the manganese atoms; ${ }^{20}$ such coupling is characteristic of dinuclear Mn bis-salens. ${ }^{30-36}$ The geometry of each complex was first optimized in the high-spin ferromagnetically coupled state, then again in the low-spin antiferromagnetically coupled state. On the basis of the calculated total energies and spin expectation values at each geometry, the magnetic coupling constant $J$ was calculated according to eq 1

$$
J=-\frac{E^{\mathrm{HS}}-E^{\mathrm{LS}}}{\left\langle\hat{S}^{2}\right\rangle^{\mathrm{HS}}-\left\langle\hat{S}^{2}\right\rangle^{\mathrm{LS}}}
$$

where $E^{\mathrm{HS}}$ and $E^{\mathrm{LS}}$ are the calculated total energy in the highspin and low-spin state, respectively, and $\left\langle\hat{S}^{2}\right\rangle^{\mathrm{HS}}$ and $\left\langle\hat{S}^{2}\right\rangle^{\mathrm{LS}}$ are the calculated spin expectation values for the high-spin and lowspin state, respectively. ${ }^{37,38}$ A negative value for $J$ indicates that the manganese atoms are antiferromagnetically coupled, while a positive value indicates ferromagnetic coupling.

Calculations of Standard Potentials. The change in free energy of oxidation, $\Delta G_{(s)}^{\circ}$, was obtained from electronic structure calculations and the free energy cycle shown in Figure 1 according to eq 2

$$
\begin{aligned}
\Delta G_{(\mathrm{s})}^{\circ} & =\Delta G_{(\mathrm{g})}^{\circ}+\Delta \Delta G_{\mathrm{sol}}^{\circ} \\
& =\Delta G_{(\mathrm{g})}^{\circ}+\Delta G_{\mathrm{sol}}^{\circ, \mathrm{ox}}-\Delta G_{\mathrm{sol}}^{\circ, \text { red }}
\end{aligned}
$$

where $\Delta G_{(\mathrm{g})}^{\circ}$ is the free energy of ionization in the gas phase and $\Delta G_{\mathrm{sol}}^{\circ}$ are the free energies of solvation.

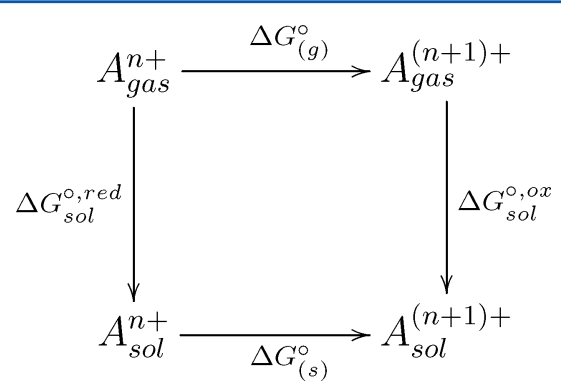

Figure 1. Thermodynamic cycle used to calculate the change in free energy of oxidation, $\Delta G_{(s)}^{\circ}$.

Absolute standard reduction potentials (vs vacuum) were calculated directly from $\Delta G_{(\mathrm{s})}^{\circ}$ using eq 3

$$
E_{(\mathrm{vac})}^{\circ}=-\frac{-\Delta G_{(\mathrm{s})}^{\circ}}{n F}
$$

where $n$ is the number of electrons transferred and $F$ is the Faraday constant.

The calculated standard reduction potentials were referenced using the method described by Batista and colleagues. ${ }^{39}$ An absolute standard reduction potential was calculated for the ferrocene/ferrocenium $\left(\mathrm{Fc}^{0 /+}\right)$ couple in acetonitrile by the 
same method described above. The calculated standard reduction potentials were then referenced to $\mathrm{Fc}^{0 /+}$ using eq 4

$$
E^{\circ}=E_{(\mathrm{vac})}^{\circ}-E_{\left(\mathrm{vac}, \mathrm{Fc} / \mathrm{Fc}^{+}\right)}^{\circ}
$$

It is often important when modeling redox potentials to consider the effects of tight ion pairing between the charged transition metal complex and the supporting electrolyte. However, as Batista and colleagues demonstrated for a highly charged ruthenium complex, the thermodynamic effect of the supporting electrolyte generally becomes smaller than the error in "state-of-the-art" calculations when a highly polar solvent such as acetonitrile is used. ${ }^{39}$ As such, we make the approximation that any thermodynamic effect from the supporting electrolyte is negligible, and we do not explicitly include it in our calculations. To support this approximation, we have examined the influence of tight-binding $\mathrm{PF}_{6}{ }^{-}$ counterions on the electronic structure and thermodynamics of the acetate-bound complex. We found that the inclusion of tight-binding counterions resulted in erroneous predictions of ferromagnetic coupling between the manganese centers when antiferromagnetic coupling was observed experimentally. Additionally, we found that the inclusion of explicit counterions resulted in a ligand-centered oxidation from $\left[\mathrm{Mn}_{2} \mathrm{LAc}\right]^{+}$to $\left[\mathrm{Mn}_{2} \mathrm{LAc}\right]^{2+}$, whereas this oxidation was experimentally determined to be metal-centered. ${ }^{5}$ As such, we concluded that the inclusion of tight-binding counterions did not give a physically accurate model.

Calculations of $\mathrm{p} K_{\mathrm{a}}^{\prime}$ 's. Free energies of deprotonation, $\Delta G_{\mathrm{a}(\mathrm{s})}^{\circ}$, were obtained from electronic structure calculations and the free energy cycle shown in Figure 2 using the equation

$$
\Delta G_{\mathrm{a}(\mathrm{s})}^{\circ}=\Delta G_{\mathrm{a}(\mathrm{g})}^{\circ}+\Delta G_{\mathrm{sol}}^{\circ, \mathrm{H}^{+}}+\Delta \Delta G_{\mathrm{sol}}^{\circ}
$$

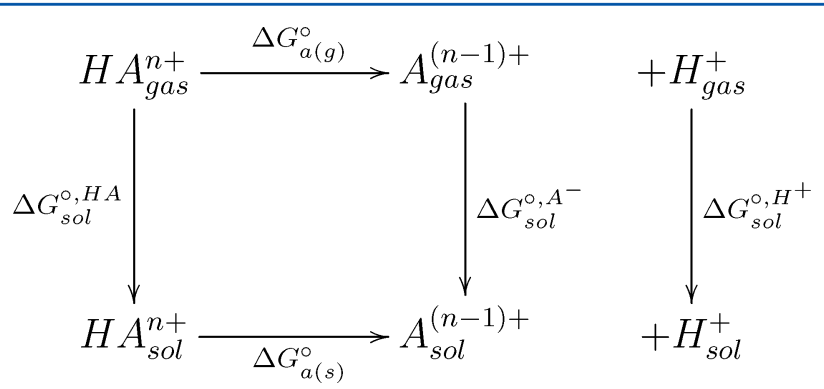

Figure 2. Thermodynamic cycle used to calculate the change in free energy of deprotonation, $\Delta G_{\mathrm{a}(\mathrm{s})}^{\circ}$. where $\Delta G_{\mathrm{a}(\mathrm{g})}^{\circ}$ is the gas-phase free energy of deprotonation; $\Delta G_{\text {sol }}^{\circ, H^{+}}$is the free energy of solvation of the proton; and $\Delta \Delta G_{\text {sol }}^{\circ}$ is the difference in free energies of solvation between the deprotonated and protonated states. A recommended value from the literature of $-260.2 \mathrm{kcal} \mathrm{mol}^{-1}$ was used for $\Delta G_{\mathrm{sol}}^{\mathrm{o}, \mathrm{H}^{+}}$in acetonitrile. $^{40}$

Calculated $\mathrm{p} K_{\mathrm{a}}$ 's were obtained from the free energy of deprotonation according to the standard equation

$$
\mathrm{p} K_{\mathrm{a}}=-\log _{10} e^{-\Delta G_{\mathrm{a}(\mathrm{s})}^{\circ} / R T}
$$

\section{RESULTS}

Model Validation. Figure 3 shows the calculated minimum-energy geometries of the first four oxidation states of the acetate-bound complex $\left[\mathrm{Mn}_{2} \mathrm{LAc}\right]^{n+}$. We have previously reported a crystal structure of $\left[\mathrm{Mn}^{\mathrm{II}}{ }_{2} \mathrm{LAc}\right]^{+}$; as such, we compared the calculated geometry of this compound to the crystal structure in order to determine whether our model could accurately predict the geometry of these complexes (Table 1). The mean difference in interatomic distances among

Table 1. Comparison of Predicted Interatomic Distances of Mn Atoms and Ligand Donor Atoms between the Calculated Structure and Experimental Crystal Structure for $\left[\mathrm{Mn}_{2}{ }_{2} \mathrm{LAc}\right]^{+}$

\begin{tabular}{lcc}
\multicolumn{1}{c}{ atoms } & DFT $(\AA)$ & difference $(\AA)$ \\
$\mathrm{Mn}-\mathrm{Mn}$ & 3.272 & 0.027 \\
$\mathrm{Mn}-\mathrm{N}(1)$ & 2.202 & 0.022 \\
$\mathrm{Mn}-\mathrm{N}(2)$ & 2.223 & 0.028 \\
$\mathrm{Mn}-\mathrm{N}(3)$ & 2.596 & 0.026 \\
$\mathrm{Mn}-\mathrm{N}(4)$ & 2.596 & 0.044 \\
$\mathrm{Mn}-\mathrm{N}(5)$ & 2.202 & 0.009 \\
$\mathrm{Mn}-\mathrm{N}(6)$ & 2.223 & 0.024 \\
$\mathrm{Mn}-\mathrm{O}(1)$ & 2.203 & 0.011 \\
$\mathrm{Mn}-\mathrm{O} \mathrm{(2)}$ & 2.195 & 0.020 \\
$\mathrm{Mn}-\mathrm{O}(3)$ & 2.081 & 0.011 \\
$\mathrm{Mn}-\mathrm{O}(4)$ & 2.195 & 0.012 \\
$\mathrm{Mn}-\mathrm{O}(5)$ & 2.203 & 0.001 \\
$\mathrm{Mn}-\mathrm{O}(6)$ & 2.081 & 0.002 \\
\hline
\end{tabular}

the $\mathrm{Mn}$ atoms and the ligand donor atoms was $0.018 \AA$, confirming that the model is able to make accurate structural predictions.

Standard reduction potentials for each subsequent oxidation in acetonitrile were calculated and are shown in Figure 3. The calculated potentials were compared to previously measured

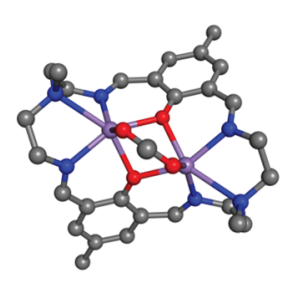

$\left[\mathrm{Mn}_{2}{ }_{2} \mathrm{LAc}\right]^{+}$

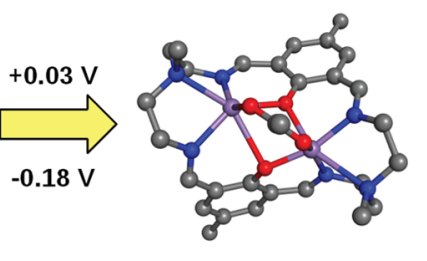

$[\mathrm{Mn} " \mathrm{Mn} \text { "'LAc }]^{2+}$

Experimental

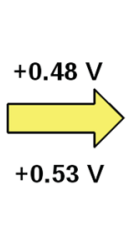

Theoretical

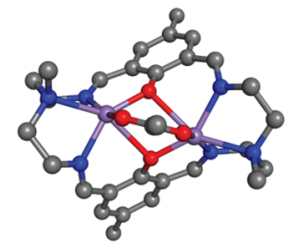

$\left[\mathrm{Mn}_{2}{ }_{2} \mathrm{LAC}\right]^{3+}$
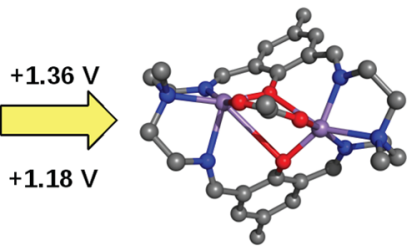

$\left[\mathrm{Mn}_{2}^{\prime \prime \prime} \mathrm{L} \cdot \mathrm{AcC}\right]^{4+}$

Figure 3. Minimum-energy geometries of the four dimanganese complexes $\left[\mathrm{Mn}_{2}^{\mathrm{II}} \mathrm{LAc}\right]^{+},\left[\mathrm{Mn}^{\mathrm{II}} \mathrm{Mn}{ }^{\mathrm{III}} \mathrm{LAc}\right]^{2+},\left[\mathrm{Mn}^{\mathrm{III}}{ }_{2} \mathrm{LAc}\right]^{3+}$, and $\left[\mathrm{Mn}{ }_{2}^{\mathrm{III}} \mathrm{LAc}\right]^{4+}$. Nonpolar hydrogen atoms have been omitted for clarity. Standard reduction potentials are referenced to $\mathrm{Fc}^{0 /+}$. 
experimental redox potentials ${ }^{5}$ from cyclic voltammetry of $\left[\mathrm{Mn}_{2}^{\mathrm{II}} \mathrm{Ac}\right]^{+}$in acetonitrile (Figure 4$)$. The first oxidation $\left(E_{\exp }^{1 / 2}\right.$

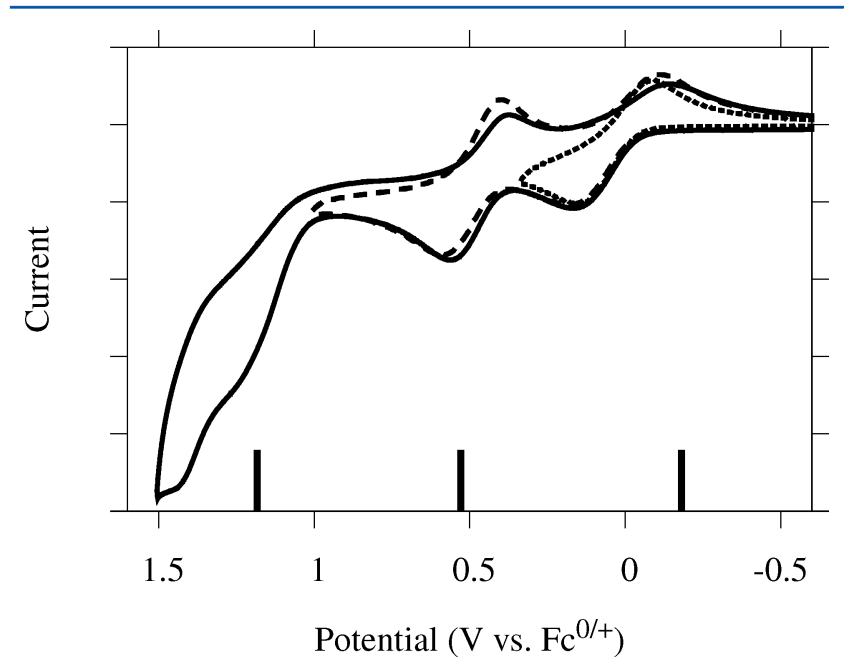

Figure 4. Experimental cyclic voltammograms (curves) and predicted redox potentials (bars) for $\left[\mathrm{Mn}_{2}^{\mathrm{II}} \mathrm{LAc}\right]^{+}$in acetonitrile solution. Experimental data were adapted from a previous study. ${ }^{5}$

$\left.=+0.03 \mathrm{~V} \mathrm{vs} \mathrm{Fc}^{0 /+}\right)$ from $\left[\mathrm{Mn}_{2}{ }_{2}^{\mathrm{II}} \mathrm{LAc}\right]^{+}$to $\left[\mathrm{Mn}^{\mathrm{II}} \mathrm{Mn}^{\mathrm{III}} \mathrm{LAc}\right]^{2+}$ was predicted at $E^{\circ}=-0.18 \mathrm{~V}$ vs $\mathrm{Fc}^{0 /+}$, the second $\left(E_{\exp }^{1 / 2}=+0.48 \mathrm{~V}\right.$

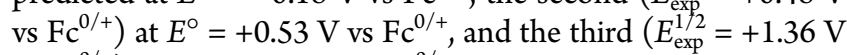
vs $\left.\mathrm{Fc}^{0 /+}\right)$ at $E^{\circ}=+1.18 \mathrm{~V}$ vs $\mathrm{Fc}^{0 /+}$. These predicted values are in excellent agreement with the experimentally measured electrochemical values; the errors are within the currently accepted limit for the accuracy of electrochemical property prediction. ${ }^{39}$ Further, the electronic structures predicted by these calculations are in good agreement with experimental results. An analysis using Bader's Atoms in Molecules theory ${ }^{28}$ showed that the electron density in the basins of the $\mathrm{Mn}$ atoms decreased significantly through the first two oxidations but remained relatively constant for the third oxidation. This indicates that the first two oxidations are predicted to be metal-centered, while the third is an oxidation of the ligand which most likely yields a phenoxy radical. This is consistent with experimental spectra. ${ }^{5}$

Modeling Electrochemical Intermediates of $\left[\mathrm{Mn}_{2} \mathrm{~L}\right]^{n+}$. Figure 5 shows the electrochemical response of $\left[\mathrm{Mn}_{2}{ }_{2} \mathrm{~L}\right]^{2+}$ in $\mathrm{MeCN}$ with $0.25 \% \mathrm{H}_{2} \mathrm{O}$ added to the solution. ${ }^{5}$ The CVs show several quasireversible waves between 0 and $+1.2 \mathrm{~V}$ and a large irreversible wave at $+1.4 \mathrm{~V}$ vs $\mathrm{Fc}^{0 /+}$. Similar $\mathrm{CVs}$ were observed in $\mathrm{PC}$ with an increase in the wave at $+1.4 \mathrm{~V}$ vs $\mathrm{Fc}^{0 /+}$ with addition of water up to $7 \%$, consistent with electrocatalytic water oxidation. 5

To provide insight into the electrochemical intermediates present in the CVs of $\left[\mathrm{Mn}_{2} \mathrm{~L}\right]^{n+}$, we applied the model described above to estimate the lowest free energy pathway for the four-electron oxidation. The model was applied to an initial set of 25 possible intermediates in the mechanism in which the molecule was varied only by removal of protons and electrons, beginning with $\left[\mathrm{Mn}_{2}{ }_{2} \mathrm{~L}\left(\mathrm{OH}_{2}\right)_{2}\right]^{2+}$ and going through $\left[\mathrm{Mn}^{\mathrm{III}}{ }_{2} \mathrm{~L}-\right.$ $\left.(\mathrm{O})_{2}\right]^{2+}$, as shown in Figure 6 . The lowest-energy pathway at neutral $\mathrm{pH}$ was chosen by following the lowest-energy steps involving an electron transfer, except for where the $\mathrm{p} K_{\mathrm{a}}$ of a deprotonation was less than 7 , in which case that step was taken. The resulting pathway is illustrated in Figure 7.

First Oxidation. The reaction pathway begins unambiguously with the concerted removal of a proton and electron from

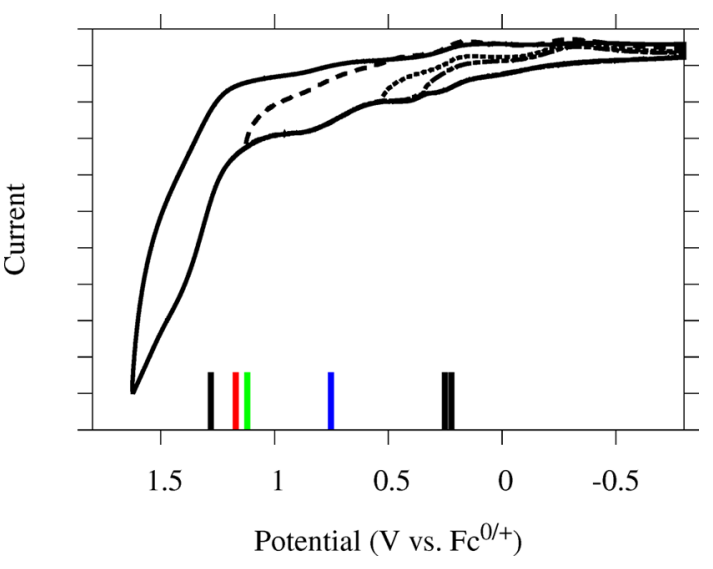

Figure 5. Cyclic voltammogram of $\left[\mathrm{Mn}_{2}^{\mathrm{II}} \mathrm{L}\left(\mathrm{OH}_{2}\right)_{2}\right]^{2+}$ in acetonitrile with $0.25 \% \mathrm{H}_{2} \mathrm{O}\left(\mathrm{vs} \mathrm{Fc}^{0} / \mathrm{Fc}^{+}\right.$). Calculated redox potentials are shown as bars. Possible third oxidations are colored: red bar, one-electron oxidation followed by deprotonation; green bar, concerted electronproton transfer; blue bar, deprotonation followed by one-electron oxidation. Experimental data were adapted from a previous study. ${ }^{5}$

$\left[\mathrm{Mn}_{2}{ }_{2}\left(\mathrm{OH}_{2}\right)_{2}\right]^{2+}$ to give $\left[\mathrm{Mn}^{\mathrm{II}} \mathrm{Mn}^{\mathrm{III}} \mathrm{L}\left(\mathrm{OH}_{2}\right)(\mathrm{OH})\right]^{2+}\left(E^{\circ}=\right.$ $+0.863 \mathrm{~V}$ vs NHE). This step is likely somewhat electrochemically irreversible in $\mathrm{MeCN}$, as the proton diffuses away from the electrode prior to subsequent reduction. In such a case, a oneelectron reduction of this complex to $\left[\mathrm{Mn}_{2}^{\mathrm{II}} \mathrm{L}\left(\mathrm{OH}_{2}\right)(\mathrm{OH})\right]^{+}$is expected $\left(E^{\circ}=+0.292 \mathrm{~V}\right.$ vs NHE). This result is in agreement with the experimental cyclic voltammogram which shows a oneelectron reduction wave at $+0.35 \mathrm{~V}$ vs NHE with the corresponding oxidation wave at $+0.8 \mathrm{~V}$ vs NHE.

Second Oxidation. The next predicted step in the reaction pathway is the one-electron oxidation of $\left[\mathrm{Mn}^{\mathrm{II}} \mathrm{Mn}^{\mathrm{III}} \mathrm{L}\left(\mathrm{OH}_{2}\right)\right.$ $(\mathrm{OH})]^{2+}$ to $\left[\mathrm{Mn}_{2}{ }_{2} \mathrm{~L}\left(\mathrm{OH}_{2}\right)(\mathrm{OH})\right]^{3+}\left(E^{\circ}=+0.892 \mathrm{~V}\right.$ vs NHE$)$. This step is $0.367 \mathrm{~V}$ lower in energy than the corresponding one-electron one-proton concerted process from $\left[\mathrm{Mn}^{\mathrm{II}} \mathrm{Mn}{ }^{\mathrm{III}} \mathrm{L}\right.$ $\left.\left(\mathrm{OH}_{2}\right)(\mathrm{OH})\right]^{2+}$ to $\left[\mathrm{Mn}_{2}{ }_{2} \mathrm{~L}(\mathrm{OH})_{2}\right]^{2+}$ as a result of the high $\mathrm{pK}{ }_{a}$ $(+19.2)$ of the deprotonation of the former to give $\left[\mathrm{Mn}^{\mathrm{II}} \mathrm{Mn}^{\mathrm{III}} \mathrm{L}(\mathrm{OH})_{2}\right]^{+}$. This is in agreement with the experimental measurement of $E_{1 / 2}$ for the second oxidation and reduction at $+0.8 \mathrm{~V}$ vs NHE. The experimentally observed oxidation wave corresponds to a two-electron process, though not necessarily one which is concerted; this further supports that the potentials of the first two oxidations are very similar.

Third Oxidation. The predicted lowest free energy pathway is the deprotonation pathway from $\left[\mathrm{Mn}^{\mathrm{III}}{ }_{2} \mathrm{~L}\left(\mathrm{OH}_{2}\right)(\mathrm{OH})\right]^{3+}$ to $\left[\mathrm{Mn}^{\mathrm{III}} \mathrm{L}(\mathrm{OH})_{2}\right]^{2+}$ followed by a subsequent oxidation to $\left[\mathrm{Mn}_{2}^{\mathrm{III}} \mathrm{L}(\mathrm{OH})_{2}\right]^{3+}$ with a predicted redox potential of +1.39 $\mathrm{V}$ vs NHE. However, it is unclear to what extent this deprotonation would occur on the catalytic time scale. It is also possible the cycle follows a pathway in which a oneelectron oxidation to $\left[\mathrm{Mn}_{2}^{\mathrm{III}} \mathrm{L}\left(\mathrm{OH}_{2}\right)(\mathrm{OH})\right]^{4+}$ is followed by deprotonation to $\left[\mathrm{Mn}_{2}^{\mathrm{III}} \mathrm{L}(\mathrm{OH})_{2}\right]^{3+}$ or through another pathway in which the third oxidation occurs as a concerted electron-proton transfer to form $\left[\mathrm{Mn}_{2}^{\mathrm{III}} \mathrm{L}(\mathrm{OH})_{2}\right]^{3+}$ directly. As these processes are similar in energy, they are likely in competition, and both occur to some extent in the catalytic cycle. In the case of the one-electron oxidation process, rapid deprotonation of $\left[\mathrm{Mn}_{2}{ }_{2} \mathrm{~L}\left(\mathrm{OH}_{2}\right)(\mathrm{OH})\right]^{3+}$ to $\left[\mathrm{Mn}^{\mathrm{III}}{ }_{2} \mathrm{~L}(\mathrm{OH})_{2}\right]^{2+}$ is expected $\left(\mathrm{p} K_{\mathrm{a}}=-0.867\right)$, and the fourth oxidation is the same for all cases as described below.

All three possible pathways for the third oxidation are notable for the noninnocent role of the ligand in the reaction. 


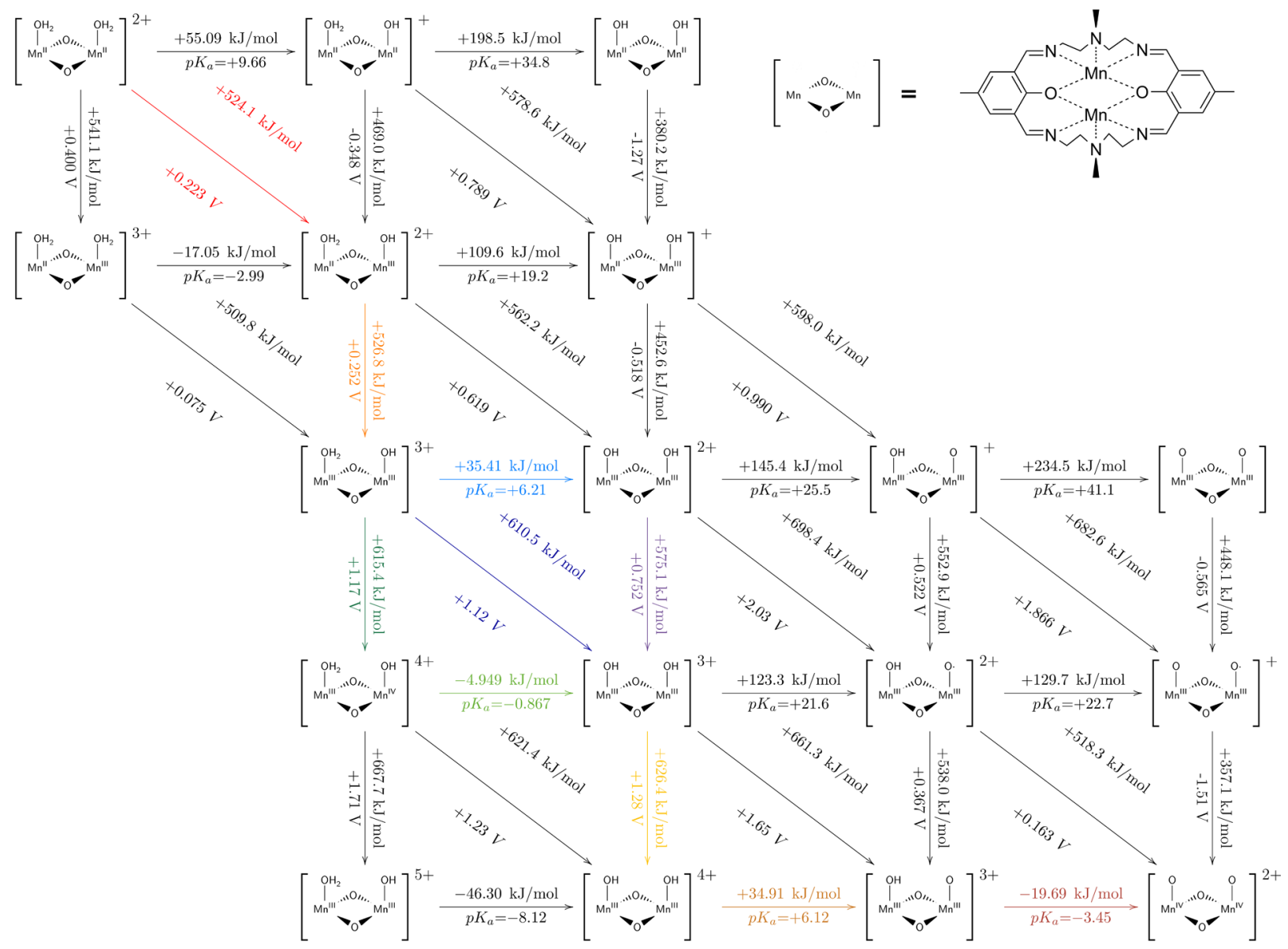

Figure 6. Predicted free energies and associated thermodynamic quantities of possible reaction intermediates in the catalytic pathway of $\left[\mathrm{Mn}_{2} \mathrm{~L}\right]^{n+}$.

Whereas the first two oxidations were metal-centered, the third oxidation involves the loss of an electron which is at least partially delocalized onto the macrocyclic ligand. This yields an intermediate bearing a ligand having radical character in its ground state. The redox potentials for the formation of this radical intermediate are significantly lower than for the corresponding ligand-centered oxidation of the acetate-bound complex to give $\left[\mathrm{Mn}^{\mathrm{III}}{ }_{2} \mathrm{LAc}\right]^{3+}\left(E^{\circ}=+1.82 \mathrm{~V}\right.$ vs $\left.\mathrm{NHE}\right)$. We attribute the destabilization of the acetate-bound radical intermediate to the need to accommodate the acetate ligand. The presence of the bridging acetate constrains the $\mathrm{Mn}-\mathrm{Mn}$ internuclear distance to $3.78 \AA$. The geometry of the hydroxobound species is able to relax to a less sterically hindered structure having a $\mathrm{Mn}-\mathrm{Mn}$ internuclear distance of $4.09 \AA$.

The predicted redox potentials for the different possible third oxidations were compared to experimental cyclic voltammetry results in order to confirm the calculations and to resolve the ambiguity of the third oxidation (Figure 5). It is clear that the third oxidation pathway in which deprotonation occurs first is present in the catalytic cycle. On the basis of the strong current observed from this oxidation, we believe that it is most likely the dominant pathway in the catalytic cycle. However, due to the proximity of the potentials of the other pathways to the onset of the observed catalytic wave, the oxidation-first and concerted pathways cannot be absolutely ruled out. Given that the magnitude of the evolved current from the deprotonationfirst pathway is similar to those of the first two oxidations, however, we suggest that the alternative pathways make relatively minor contributions to the overall electrochemical behavior in acetonitrile.

Fourth Oxidation. The fourth oxidation is predicted to occur by the removal of one electron from $\left[\mathrm{Mn}_{2}{ }_{2} \mathrm{~L}(\mathrm{OH})_{2}\right]^{2+}$ to give $\left[\mathrm{Mn}_{2}^{\mathrm{III}} \mathrm{L}(\mathrm{OH})_{2}\right]^{3+}$ with a predicted redox potential of $+1.92 \mathrm{~V}$ vs NHE. As with the previous oxidation, this oxidation has a considerable amount of ligand character and most likely represents the formation of a species formally having two phenoxy radicals. The predicted redox potential is close to the potential at which a catalytic wave is observed in the $\mathrm{CV}$ (Figure 5). On the basis of this similarity with experiment, we identify the catalytically active species as $\left[\mathrm{Mn}_{2}^{\mathrm{III}}{ }_{2} \mathrm{~L}(\mathrm{OH})_{2}\right]^{3+}$.

Most reported manganese water oxidation complexes that catalyze the oxidation of water are not known to undergo ligand oxidation. ${ }^{41-43}$ However, there are notable examples of catalytic cycles involving ligand oxidation in water oxidation catalysts containing other transition metals, most notably the ruthenium dimer of Tanaka and colleagues. ${ }^{44}$ The Tanaka catalyst has a number of structural similarities to $\left[\mathrm{Mn}_{2} \mathrm{~L}\right]$ including the relative cis orientation of the bound waters.

Reactions of the Catalytically Active Species. Following the first four oxidations, two protons are removed successively $\left(\mathrm{p} K_{\mathrm{a}}{ }^{\prime} \mathrm{s}=+6.12,-3.45\right)$ to give $\left[\mathrm{Mn}^{\mathrm{III}}{ }_{2} \mathrm{~L}(\mathrm{OH})(\mathrm{O})\right]^{3+}$ followed by $\left[\mathrm{Mn}^{\mathrm{IV}}{ }_{2} \mathrm{~L}\left(\mathrm{O}_{2}\right)\right]^{2+}$. This final state is interesting for the behavior of its two coordinated oxo ligands. Figure 8 shows the calculated minimum-energy geometry of this complex; in this state, the two oxo ligands spontaneously approach an internuclear distance of $1.397 \AA$ and form a covalent bond having a calculated bond order of 0.97 (Table S4 in the 


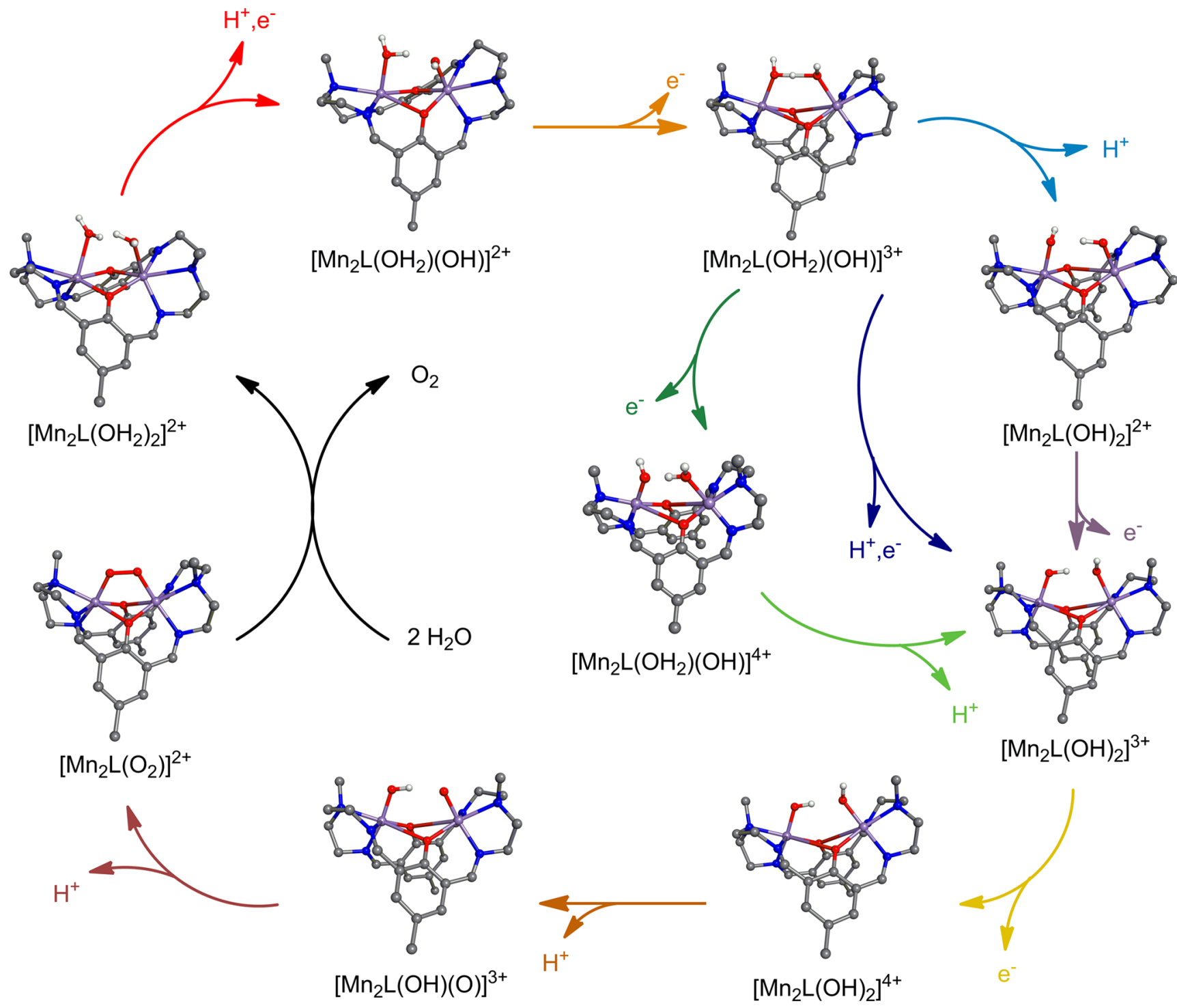

Figure 7. Predicted lowest-energy reaction pathways in acetonitrile solution. Three possible competing routes for the third oxidation are shown.

Supporting Information). This is consistent with other Mn species which coordinate a peroxo ligand. This process is quite thermodynamically favorable; the removal of the last proton leaves the complex with two (formally) $\mathrm{O}^{2-}$ ligands in close proximity. The resulting large Coulombic repulsion provides a large thermodynamic driving force for the donation of electron density from the oxo ligands into the $\mathrm{d}$ orbitals of the $\mathrm{Mn}$ atoms, which in turn donate electron density through backbonding into the phenoxy radicals of the macrocyclic ligand. With the Coulombic repulsion relieved, the $\mathrm{O}$ atoms spontaneously approach and form a covalent $\mathrm{O}-\mathrm{O}$ bond which creates an even larger thermodynamic driving force. With each of these factors contributing a large thermodynamic stabilization, it comes as no surprise that the final $\mathrm{p} K_{\mathrm{a}}$ is negative.

We cannot rule out the possibility of oxygen formation by nucleophilic attack by a solvated water molecule on the metaloxo species $\left[\mathrm{Mn}^{\mathrm{III}}{ }_{2} \mathrm{~L}(\mathrm{OH})(\mathrm{O})\right]^{3+}$. However, given the negative $\mathrm{pK}_{\mathrm{a}}$ of the deprotonation of this species and the low concentration of water in the acetonitrile solution, we consider oxygen formation by an intramolecular nucleophilic attack to be more likely.
The formation of an $\mathrm{O}-\mathrm{O}$ moiety has been reported in theoretical studies of other water oxidation catalysts; however, previous studies in the literature have for the most part only found intramolecular $\mathrm{O}-\mathrm{O}$ bond formation when the solvent is treated explicitly. ${ }^{45}\left[\mathrm{Mn}_{2} \mathrm{~L}\right]$ thus represents a rare case where the $\mathrm{O}-\mathrm{O}$ formation is predicted with only an implicit solvation model. This emphasizes the potential for this novel water oxidation catalyst to undergo intramolecular reactions.

We believe that diatomic oxygen is likely formed in the catalytic cycle through dissociaton of this $\mathrm{O}-\mathrm{O}$ moiety from this complex. Given that this complex is believed to exist as a broken-symmetry singlet, the most direct pathway to $\mathrm{O}_{2}$ release would seem to be the dissociation of singlet oxygen. DFT calculations of this pathway show that this reaction is uphill by $+101.3 \mathrm{~kJ} / \mathrm{mol}$, and thus the equilibrium is heavily reactantfavored. However, given that the released $\mathrm{O}_{2}$ will quickly diffuse away, it is possible that this pathway can lead to the formation of significant quantities of singlet oxygen. The other likely pathway presumably entails a spin crossover of the complex to a triplet state followed by dissociation of triplet oxygen to leave the unbound catalyst in a singlet state (Figure $\mathrm{S} 1$ in the Supporting Information); however, we have left the detailed 


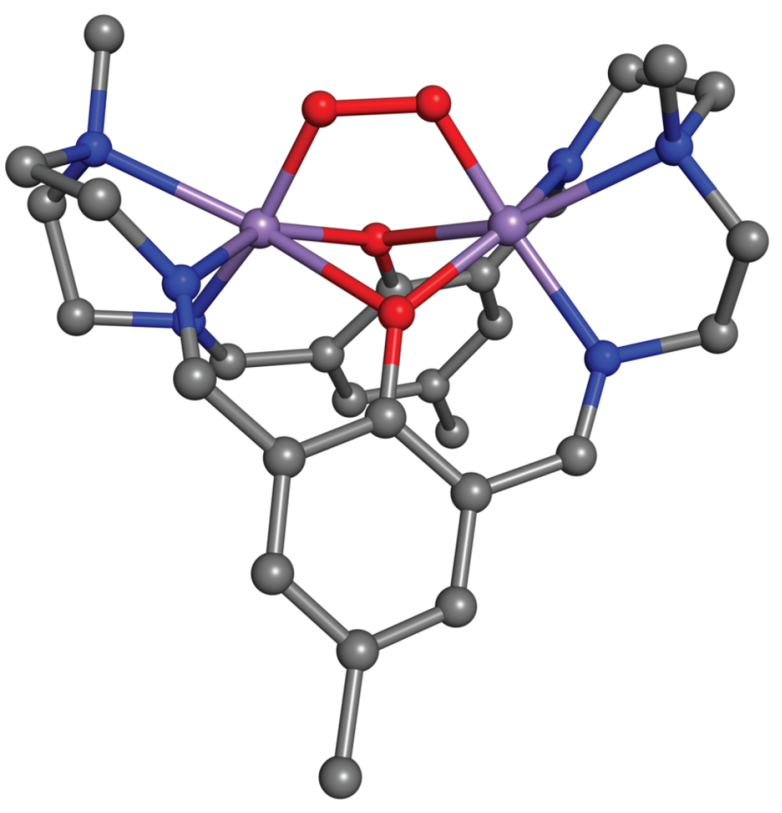

Figure 8. Predicted gas-phase geometry of $\left[\mathrm{Mn}_{2} \mathrm{~L}\left(\mathrm{O}_{2}\right)\right]^{2+}$ with $\mathrm{O}-\mathrm{O}$ internuclear distance of $1.397 \AA$. Hydrogen atoms have been omitted for clarity.

examination of this pathway to a future study due to the challenges of modeling spin crossovers using a singledeterminant DFT method. Even so, it is clear that the release of oxygen is not the thermodynamically limiting step in the catalytic cycle.

The broken symmetry approximation was justified by calculating magnetic coupling constants for each species involved in the catalytic cycle and showing that the broken symmetry structure was more favorable (Table 2 and Table S5, Supporting Information). This antiferromagnetic coupling is rather weak, typically on the order of several wavenumbers. Perhaps most notable is the antiferromagnetic coupling exhibited by $\left[\mathrm{Mn}^{\mathrm{IV}}{ }_{2} \mathrm{~L}\left(\mathrm{O}_{2}\right)\right]^{2+}$, where the strong covalent interaction between the two bound oxos is accompanied by a coupling constant of $-1090 \mathrm{~cm}^{-1}$. This is 2 orders of magnitude larger than for any other species believed to be involved in the catalytic cycle, and it is indicative of the strong multireference nature of the final state of the complex. The only ferromagnetically coupled species believed to be involved in the catalytic cycle is $\left[\mathrm{Mn}_{2}{ }_{2} \mathrm{~L}(\mathrm{OH})(\mathrm{O})\right]^{3+}\left(\mathrm{J}=+0.36 \mathrm{~cm}^{-1}\right)$. The calculated difference in energy between the high-spin state and the broken symmetry singlet is only $0.05 \mathrm{~kJ} \mathrm{~mol}^{-1}$, and so it is quite possible that the relative ordering of the potential energy surfaces for this state is predicted incorrectly by the B3LYP functional. Assuming this high-spin state, the final deprotonation to give high-spin $\left[\mathrm{Mn}^{\mathrm{IV}}{ }_{2} \mathrm{~L}\left(\mathrm{O}_{2}\right)\right]^{2+}$ is uphill by approximately $600 \mathrm{~kJ} \mathrm{~mol}^{-1}(\mathrm{pK}, \sim 105)$. Given this, the most likely kinetic pathway at room temperature involves some form of nonadiabatic process (i.e., following a nearby minimum-energy crossing seam) to the broken symmetry singlet. As a result, this possible ferromagnetic coupling does not affect the results predicted by treating the catalyst as a broken symmetry singlet throughout the cycle.

On the basis of these results, it is clear that the overpotentialdetermining step in the catalytic cycle is the oxidation of $\left[\mathrm{Mn}_{2}{ }_{2} \mathrm{~L}(\mathrm{OH})_{2}\right]^{3+}$ to $\left[\mathrm{Mn}_{2}^{\mathrm{III}}{ }_{2} \mathrm{~L}(\mathrm{OH})_{2}\right]^{4+}$, as it has the highest redox potential of any step in the mechanism. As the fourth oxidation is predicted to have a redox potential of $E^{\circ}=+1.92 \mathrm{~V}$ vs NHE, we expect the inefficiency of this step to result in a significant overpotential as is observed experimentally. Alternative reaction pathways to this step, such as a oneelectron, one-proton step which might be thought to lower the overpotential by eliminating charge buildup, are even more inefficient $\left(E^{\circ}=+2.29 \mathrm{~V}\right.$ vs NHE for $\left[\mathrm{Mn}_{2}{ }_{2} \mathrm{~L}(\mathrm{OH})_{2}\right]^{3+}$ to $\left[\mathrm{Mn}^{\mathrm{III}}{ }_{2} \mathrm{~L}(\mathrm{OH})(\mathrm{O})\right]^{3+}$ ) due to the large barrier to deprotonation $\left(\mathrm{p} K_{\mathrm{a}}=+21.6\right.$ for $\left.\left[\mathrm{Mn}_{2}^{\mathrm{III}} \mathrm{L}(\mathrm{OH})_{2}\right]^{3+}\right)$. To move toward a reasonable efficiency, future developments of this catalyst system will need to reduce this overpotential by either stabilizing $\left[\mathrm{Mn}_{2}^{\mathrm{III}} \mathrm{L}(\mathrm{OH})_{2}\right]^{4+}$, thereby lowering the corresponding redox potential, or by stabilizing $\left[\mathrm{Mn}_{2}^{\mathrm{III}}{ }_{2} \mathrm{~L}(\mathrm{OH})(\mathrm{O})\right]^{2+}$ in order to lower the corresponding barrier to deprotonation of and consequently lowering $E^{\circ}$ for the corresponding oneelectron, one-proton step.

\section{CONCLUSIONS}

We have demonstrated that unrestricted density functional theory using the B3LYP hybrid functional and the broken symmetry approximation is capable of reproducing the electrochemical behavior of the dimanganese tetrakis-Schiff base complex $\left[\mathrm{Mn}_{2}{ }_{2} \mathrm{~L}\left(\mathrm{OH}_{2}\right)_{2}\right]^{2+}$ in acetonitrile solution. These results are in excellent agreement with electrochemical studies in acetonitrile solution. We have also demonstrated that the formation of an $\mathrm{O}-\mathrm{O}$ single bond occurs during the deprotonation of $\left[\mathrm{Mn}_{2}^{\mathrm{III}} \mathrm{L}(\mathrm{OH})\left(\mathrm{O}^{*}\right)\right]^{3+}$ leading to the subsequent release of $\mathrm{O}_{2}$ and, presumably, regeneration of the catalyst.

The thermodynamic efficiency of water oxidation in acetonitrile solution is limited by the one-electron oxidation from $\left[\mathrm{Mn}_{2}^{\mathrm{III}} \mathrm{L}(\mathrm{OH})_{2}\right]^{3+}$ to $\left[\mathrm{Mn}^{\mathrm{III}}{ }_{2} \mathrm{~L}(\mathrm{OH})_{2}\right]^{4+}$. We have

Table 2. Magnetic Coupling Constant Data for Intermediates Believed to Be Involved in the Catalytic Cycle ${ }^{a}$

\begin{tabular}{|c|c|c|c|c|c|}
\hline Compound & $E^{\mathrm{HS}}\left(E_{\mathrm{h}}\right)$ & $E^{\mathrm{LS}}\left(E_{\mathrm{h}}\right)$ & $\left\langle\hat{S}^{2}\right\rangle^{\mathrm{HS}}$ & $\left\langle\hat{S}^{2}\right\rangle^{\mathrm{LS}}$ & $J\left(\mathrm{~cm}^{-1}\right)$ \\
\hline$\left[\mathrm{Mn}_{2}^{\mathrm{II}} \mathrm{L}\left(\mathrm{OH}_{2}\right)_{2}\right]^{2+}$ & -4022.71357385 & -4022.71385504 & 30.0088 & 5.0031 & -2.47 \\
\hline$\left[\mathrm{Mn}_{2}{ }_{2}^{\mathrm{II}} \mathrm{L}\left(\mathrm{OH}_{2}\right)(\mathrm{OH})\right]^{+}$ & -4022.39430937 & -4022.39466708 & 30.0080 & 5.0031 & -3.14 \\
\hline$\left[\mathrm{Mn}^{\mathrm{II}} \mathrm{Mn}{ }^{\mathrm{III}} \mathrm{L}\left(\mathrm{OH}_{2}\right)(\mathrm{OH})\right]^{2+}$ & -4022.09957043 & -4022.09984172 & 24.7934 & 4.7856 & -2.98 \\
\hline$\left[\mathrm{Mn}_{2}{ }_{2} \mathrm{LI}\left(\mathrm{OH}_{2}\right)(\mathrm{OH})\right]^{3+}$ & -4021.67368785 & -4021.67380337 & 20.1016 & 4.1001 & -1.58 \\
\hline$\left[\mathrm{Mn}_{2}{ }_{2}^{\mathrm{III}} \mathrm{L}\left(\mathrm{OH}_{2}\right)(\mathrm{OH})\right]^{4+}$ & -4021.13023446 & -4021.13016353 & 16.7836 & 4.7890 & 1.30 \\
\hline$\left[\mathrm{Mn}_{2}{ }_{2}^{\mathrm{III}} \mathrm{L}(\mathrm{OH})_{2}\right]^{2+}$ & -4021.46207272 & -4021.46230694 & 20.0873 & 4.0787 & -3.21 \\
\hline$\left[\mathrm{Mn}_{2}{ }_{2}^{\mathrm{III}} \mathrm{L}(\mathrm{OH})_{2}\right]^{3+}$ & -4021.01209354 & -4021.01631499 & 16.7174 & 4.6629 & -76.9 \\
\hline$\left[\mathrm{Mn}_{2}{ }_{2} \mathrm{LI}(\mathrm{OH})_{2}\right]^{4+}$ & -4020.47098411 & -4020.47112444 & 13.9745 & 4.9751 & -3.42 \\
\hline$\left[\mathrm{Mn}_{2}^{\mathrm{III}} \mathrm{L}(\mathrm{OH})(\mathrm{O})\right]^{3+}$ & -4020.33908943 & -4020.33907071 & 13.1467 & 1.6474 & 0.36 \\
\hline$\left[\mathrm{Mn}_{2}{ }_{2}^{\mathrm{III}} \mathrm{L}\left(\mathrm{O}_{2}\right)\right]^{2+}$ & -4020.10965188 & -4020.15532153 & 13.2889 & 4.0985 & -1090 \\
\hline
\end{tabular}

${ }^{a}$ Energies are total energies calculated at the UB3LYP/6-311G(d,p)/6-311G(2df) level of theory in the gas phase. 
subsequently identified two approaches to improving the thermodynamic efficiency. Future developments of this catalyst system will need to either incorporate ligand modifications to stabilize the intermediate $\left[\mathrm{Mn}_{2}^{\mathrm{III}}{ }_{2} \mathrm{~L}(\mathrm{OH})_{2}\right]^{4+}$ or incorporate ligand modifications to lower the barrier to deprotonation of $\left[\mathrm{Mn}_{2}^{\mathrm{III}} \mathrm{L}(\mathrm{OH})_{2}\right]^{3+}$.

\section{ASSOCIATED CONTENT}

\section{S Supporting Information}

Additional structural figures; selected interatomic distances; calculated $\mathrm{Mn}-\mathrm{O}$ bond orders; nuclear coordinates; and spin population analyses. This material is available free of charge via the Internet at http://pubs.acs.org.

\section{AUTHOR INFORMATION}

\section{Corresponding Author}

*E-mail: dinolp@rpi.edu. Phone: (518) 276-2326. Fax: (518) 276-4887.

\section{Notes}

The authors declare no competing financial interest.

\section{ACKNOWLEDGMENTS}

This work was supported in part by Rensselaer Polytechnic Institute and the New York State Energy Research and Development Authority (Award No. 30940). This work used the Extreme Science and Engineering Discovery Environment (XSEDE), which is supported by National Science Foundation grant number OCI-1053575. Helpful discussions and initial computational resources were provided by Dr. Curt Breneman. J.R.B. acknowledges support from a Darrin Foundation summer fellowship through Rensselaer Polytechnic Institute.

\section{REFERENCES}

(1) Lewis, N. S.; Nocera, D. G. Powering the Planet: Chemical Challenges in Solar Energy Utilization. Proc. Natl. Acad. Sci. U.S.A. 2006, 103, 15729-15735.

(2) Siegbahn, P. E. M. Theoretical Studies of O-O Bond Formation in Photosystem II. Inorg. Chem. 2008, 47, 1779-1786.

(3) McEvoy, J. P.; Brudvig, G. W. Water-Splitting Chemistry of Photosystem II. Chem. Rev. (Washington, DC, U. S.) 2006, 106, 44554483.

(4) Kal, S.; Filatov, A. S.; Dinolfo, P. H. Structural, Electrochemical, and Spectroscopic Investigation of Acetate Bridged Dinuclear TetrakisSchiff Base Macrocycles of Mn and Zn. Inorg. Chem. 2013, 52, 1396313973.

(5) Kal, S.; Ayensu-Mensah, L.; Dinolfo, P. H. Evidence for Catalytic Water Oxidation by a Dimanganese Tetrakis-Schiff Base Macrocycle. Inorg. Chim. Acta 2014, 423, 201-206.

(6) Baik, M.-H.; Friesner, R. A. Computing Redox Potentials in Solution: Density Functional Theory as A Tool for Rational Design of Redox Agents. J. Phys. Chem. A 2002, 106, 7407-7412.

(7) Roy, L. E.; Jakubikova, E.; Guthrie, M. G.; Batista, E. R. Calculation of One-Electron Redox Potentials Revisited. Is It Possible to Calculate Accurate Potentials with Density Functional Methods? J. Phys. Chem. A 2009, 113, 6745-6750.

(8) Chiorescu, I.; Deubel, D. V.; Arion, V. B.; Keppler, B. K. Computational Electrochemistry of Ruthenium Anticancer Agents. Unprecedented Benchmarking of Implicit Solvation Methods. J. Chem. Theory Comput. 2008, 4, 499-506.

(9) Li, J.; Fisher, C. L.; Chen, J. L.; Bashford, D.; Noodleman, L. Calculation of Redox Potentials and pKa Values of Hydrated Transition Metal Cations by a Combined Density Functional and Continuum Dielectric Theory. Inorg. Chem. 1996, 35, 4694-4702.
(10) Moens, J.; Jaque, P.; De Proft, F.; Geerlings, P. The Study of Redox Reactions on the Basis of Conceptual DFT Principles: EEM and Vertical Quantities. J. Phys. Chem. A 2008, 112, 6023-6031.

(11) Galstyan, A.; Knapp, E.-W. Accurate Redox Potentials of Mononuclear Iron, Manganese, and Nickel Model Complexes. J. Comput. Chem. 2009, 30, 203-211.

(12) Wang, T.; Brudvig, G.; Batista, V. S. Characterization of Proton Coupled Electron Transfer in a Biomimetic Oxomanganese Complex: Evaluation of the DFT B3LYP Level of Theory. J. Chem. Theory Comput. 2010, 6, 755-760.

(13) Wang, T.; Brudvig, G. W.; Batista, V. S. Study of Proton Coupled Electron Transfer in a Biomimetic Dimanganese Water Oxidation Catalyst with Terminal Water Ligands. J. Chem. Theory Comput. 2010, 6, 2395-2401.

(14) Kang, R.; Yao, J.; Chen, H. Are DFT Methods Accurate in Mononuclear Ruthenium-Catalyzed Water Oxidation? An ab Initio Assessment. J. Chem. Theory Comput. 2013, 9, 1872-1879.

(15) Kwapien, K.; Piccinin, S.; Fabris, S. Energetics of Water Oxidation Catalyzed by Cobalt Oxide Nanoparticles: Assessing the Accuracy of DFT and DFT+U Approaches against Coupled Cluster Methods. J. Phys. Chem. Lett. 2013, 4, 4223-4230.

(16) Mom, R. V.; Cheng, J.; Koper, M. T. M.; Sprik, M. Modeling the Oxygen Evolution Reaction on Metal Oxides: The Infuence of Unrestricted DFT Calculations. J. Phys. Chem. C 2014, 118, 40954102.

(17) Stamenkovic, V. R.; Fowler, B.; Mun, B. S.; Wang, G.; Ross, P. N.; Lucas, C. A.; Markovic, N. M. Improved Oxygen Reduction Activity on Pt $3 \mathrm{Ni}(111)$ via Increased Surface Site Availability. Science 2007, 315, 493-497.

(18) Frisch, M. J.; Trucks, G. W.; Schlegel, H. B.; Scuseria, G. E.; Robb, M. A.; Cheeseman, J. R.; Scalmani, G.; Barone, V.; Mennucci, B.; Petersson, G. A. et al. Gaussian 09, Revision D.01; Gaussian Inc.: Wallingford CT, 2009.

(19) Leffler, J. E.; Grunwald, E. Rates and Equilibria of Organic Reactions as Treated by Statistical, Thermodynamic, and Extrathermodynamic Methods; Wiley: New York, 1963.

(20) Noodleman, L.; Davidson, E. R. Ligand Spin Polarization and Antiferromagnetic Coupling in Transition Metal Dimers. Chem. Phys. 1986, 109, 131-143.

(21) Becke, A. D. Density-Functional Thermochemistry. III. The Role of Exact Exchange. J. Chem. Phys. 1993, 98, 5648-5652.

(22) Krishnan, R.; Binkley, J. S.; Seeger, R; Pople, J. A. SelfConsistent Molecular Orbital Methods. XX. A Basis Set for Correlated Wave Functions. J. Chem. Phys. 1980, 72, 650-654.

(23) Wachters, A. J. H. Gaussian Basis Set for Molecular Wavefunctions Containing Third-Row Atoms. J. Chem. Phys. 1970, 52, 1033-1036.

(24) Kendall, R. A.; Dunning, T. H.; Harrison, R. J. Electron Affinities of the First-Row Atoms Revisited. Systematic Basis Sets and Wave Functions. J. Chem. Phys. 1992, 96, 6796-6806.

(25) Cancès, E.; Mennucci, B.; Tomasi, J. A New Integral Equation Formalism for the Polarizable Continuum Model: Theoretical Background and Applications to Isotropic and Anisotropic Dielectrics. J. Chem. Phys. 1997, 107, 3032-3041.

(26) Gorelsky, S. I. AOMix: Program for Molecular Orbital Analysis, Version 6.85, 2013; http://www.sg-chem.net/.

(27) Gorelsky, S. I.; Lever, B. P. Electronic Structure and Spectra of Ruthenium Diimine Complexes by Density Functional Theory and INDO/S. Comparison of the Two Methods. J. Organomet. Chem. 2001, 635, 187-196.

(28) Bader, R. F. W. A Quantum Theory of Molecular Structure and its Applications. Chem. Rev. 1991, 91, 893-928.

(29) Lu, T.; Chen, F. Multiwfn: A Multifunctional Wavefunction Analyzer. J. Comput. Chem. 2012, 33, 580-592.

(30) Chang, H. R.; Larsen, S. K.; Boyd, P. D. W.; Pierpont, C. G.; Hendrickson, D. N. Valence Trapping in Mixed-Valence Manganese(II)-Manganese(III) Complexes of a Macrocyclic Binucleating Ligand. J. Am. Chem. Soc. 1988, 110, 4565-4576. 
(31) Qian, M.; Gou, S.; Chantrapromma, S.; Raj, S. S.; Fun, H.-K.; Zeng, Q.; Yu, Z.; You, X. Synthesis of Dinuclear Metal Complexes of a Macrocyclic Ligand with Multi-Ligating Pendant-Arms. Crystal Structures of its Manganese(II) and Cadmium(II) complexes. Inorg. Chim. Acta 2000, 305, 83-90.

(32) Qian, M.; Gou, S.; Yu, Z.; Ju, H.; Xu, Y.; Duan, C.; You, X. Synthesis, Crystal Structure and Properties of a Macrocyclic Dinuclear Manganese(II) Complex with Functional o-Methylenephenolic Pendant Arms. Inorg. Chim. Acta 2001, 317, 157-162.

(33) Downard, A. J.; McKee, V.; Tandon, S. S. Binuclear Manganese(II) and Nickel(II) Complexes with a Potentially Octadentate Macrocyclic Ligand (H4L1): Synthesis and Characterisation. X-ray Crystal Structures of $[\mathrm{Mn} 2(\mathrm{H} 2 \mathrm{~L} 1)(\mathrm{CH} 3 \mathrm{COO}) 2]$ $2 \mathrm{CH} 3 \mathrm{OH}$ and $[\mathrm{Ni2}(\mathrm{H} 2 \mathrm{~L} 1)(\mathrm{H} 2 \mathrm{O}) 2 \mathrm{Cl} 2] 2 \mathrm{H} 20$. Inorg. Chim. Acta 1990, 173, 181-190.

(34) Lambert, S. L.; Hendrickson, D. N. Magnetic Exchange Interactions in Binuclear Transition-Metal Complexes. 20. Variation in Magnetic Exchange Interaction for a Series of Metal(II) Complexes of a Binucleating Ligand. Inorg. Chem. 1979, 18, 2683-2686.

(35) Timken, M. D.; Marritt, W. A.; Hendrickson, D. N.; Gagne, R. A.; Sinn, E. Magnetic Exchange Interactions in Binuclear TransitionMetal Complexes of a Binucleating Clathrochelate Ligand. Inorg. Chem. 1985, 24, 4202-4208.

(36) Aono, T.; Wada, H.; Yonemura, M.; Ohba, M.; Okawa, H.; E. Fenton, D. Effect of Ring Size in Macrocyclic Dinuclear Manganese(II) Complexes Upon their Structure, Properties and Reactivity towards H2O2. J. Chem. Soc., Dalton Trans. 1997, 1527-1532.

(37) Noodleman, L. Valence Bond Description of Antiferromagnetic Coupling in Transition Metal Dimers. J. Chem. Phys. 1981, 74, 57375743.

(38) Soda, T.; Kitagawa, Y.; Onishi, T.; Takano, Y.; Shigeta, Y.; Nagao, H.; Yoshioka, Y.; Yamaguchi, K. Ab Initio Computations of Effective Exchange Integrals for $\mathrm{H}-\mathrm{H}, \mathrm{H}-\mathrm{He}-\mathrm{H}$ and $\mathrm{Mn} 2 \mathrm{O} 2$ Complex: Comparison of Broken-Symmetry Approaches. Chem. Phys. Lett. 2000, $319,223-230$.

(39) Konezny, S. J.; Doherty, M. D.; Luca, O. R.; Crabtree, R. H.; Soloveichik, G. L.; Batista, V. S. Reduction of Systematic Uncertainty in DFT Redox Potentials of Transition-Metal Complexes. J. Phys. Chem. C 2012, 116, 6349-6356.

(40) Kelly, C. P.; Cramer, C. J.; Truhlar, D. G. Single-Ion Solvation Free Energies and the Normal Hydrogen Electrode Potential in Methanol, Acetonitrile, and Dimethyl Sulfoxide. J. Phys. Chem. B 2007, $111,408-422$.

(41) Limburg, J.; Vrettos, J. S.; Chen, H.; de Paula, J. C.; Crabtree, R. H.; Brudvig, G. W. Characterization of the O2-Evolving Reaction Catalyzed by $[($ terpy $)(\mathrm{H} 2 \mathrm{O}) \mathrm{MnIII}(\mathrm{O}) 2 \mathrm{MnIV}(\mathrm{OH} 2)($ terpy) $](\mathrm{NO} 3)$ 3 (terpy $=2,2: 6,2$-Terpyridine). J. Am. Chem. Soc. 2001, 123, 423-430.

(42) Naruta, Y.; Sasayama, M.-a.; Sasaki, T. Oxygen Evolution by Oxidation of Water with Manganese Porphyrin Dimers. Angew. Chem., Int. Ed. Engl. 1994, 33, 1839-1841.

(43) Kärkäs, M. D.; Johnston, E. V.; Verho, O.; A kermark, B. Artificial Photosynthesis: From Nanosecond Electron Transfer to Catalytic Water Oxidation. Acc. Chem. Res. 2014, 47, 100-111.

(44) Wada, T.; Tsuge, K.; Tanaka, K. Syntheses and Redox Properties of Bis(hydroxoruthenium) Complexes with Quinone and Bipyridine Ligands. Water-Oxidation Catalysis. Inorg. Chem. 2001, 40, 329-337.

(45) Mavros, M. G.; Tsuchimochi, T.; Kowalczyk, T.; McIsaac, A.; Wang, L.-P.; Voorhis, T. V. What Can Density Functional Theory Tell Us about Artificial Catalytic Water Splitting? Inorg. Chem. 2014, 53, 6386-6397.

\section{NOTE ADDED AFTER ASAP PUBLICATION}

This paper was published to the Web on November 5, 2014, with errors in Figures 6 and 7. This was fixed in the version published on November 13, 2014. 